\title{
Historicizing memory
}

Theory \& Psychology 22(3) 370-373

(C) The Author(s) 2012

Reprints and permission:

sagepub.co.uk/journalsPermissions.nav DOI: 10.1 I77/09593543||430736

tap.sagepub.com

@SAGE

Kurt Danziger, Marking the Mind:A History of Memory.

Cambridge, UK: Cambridge University Press, 2008. 305 pp. ISBN 978052 I 898 I 57 (hbk.).

Reviewed by: Jens Brockmeier, Free University Berlin \& University of Manitoba

As long as there has been academic psychology, there has been the lament about the fragmentation and reduction of its subject matter-if we assume for a moment that there has ever been agreement about what its subject matter is. It is true, there have been only very few developed attempts to take a stand against the parochial and reductionist tendencies and to conceptually synthesize the numerous psychological fields of study concerned with the human being in the world; and there have been even fewer that have tackled this undertaking in both a systematically and historically comprehensive manner. It is also true that psychology as an academic institution does not foster the kind of intellectual mind set required for such an enterprise. After all, its claim is to be scientific and not historical, experimental and not conceptual, evidence-based and not self-reflexive (again, let's assume for a moment that these are real oppositions).

But there are a few exceptions, psychology-theorists profoundly familiar with both intellectual cultures. One is Kurt Danziger. In the world of contemporary academia, Danziger's work is unique. It blends immense knowledge of the history (and pre-history) of psychological research with likewise immense knowledge of psychology's conceptual and cultural history; it combines discussion of empirical experimentation with its discourse analysis; and it draws on registers of historical erudition and philosophical acumen unusual in many human sciences and very rare in psychology. In today's psychology, Kurt Danziger appears like one of the small number of scholars from ancient Athens who, after Greece was defeated, were able continue their work in Rome, reminding the Romans of a civilization so different from theirs.

After his path-breaking historical discourse analyses of the emergence of his discipline, Constructing the Subject: Historical Origins of Psychological Research (1990), and of the conceptual building material that made this construction possible, Naming the Mind: How Psychology Found its Language (1997), Danziger has presented a new work on the history of memory that is similarly magisterial in scope and execution. History, however, has a different meaning here than in traditional historical accounts of scientific research. Almost always, psychology has investigated whatever it conceived as its subject-matter as though it belonged to an ahistorical human nature. What is seen as changing are the different theories about this subject which, in the classical picture, are precursors of the 
respective present theory which is considered to be the only truly scientific one. To a very large extent, this scientific progress narrative still represents the epistemological consciousness of the laboratory world of psychological memory research, irrespective of all objections and criticisms from historians and philosophers of science.

The understanding of history that Danziger unfolds in Marking the Mind: A History of Memory breaks radically with this picture. Challenging the idea, common not only in psychology and neuroscience, of human memory as a species-wide and generic, biologically given capacity, memory is historicized on three levels. The first level, interestingly enough, is approached from an evolutionary perspective. It turns out, however, that most of our specific human practices of remembering and forgetting have not emerged through biological adaptation. Like language and other practices of human sign-mediated communication, they have come into existence in a process of biological-cultural co-evolution in which the cultural dynamic became more and more dominant. Skills such as writing and social technologies such as literacy developed entirely as cultural, and not biological, achievements; and so did the kind of cognition they involved and the institutional organization they entailed. But literacy and memory are not just loosely linked. One of Danziger's main theses is that they are intrinsically intertwined. Only after the emergence of writing and the establishment of a culture of literacy in ancient Greece was "memory" named, perceived, and defined - as in the writings of Plato and Aristotle - as a distinguishable feature. What is more, it became an entity on its own. At least to those able to write and to read it seemed that with writing definitive versions of verbal texts, mnemonic inscriptions that could be kept, re-read, and reproduced could be brought into existence.

Before the written conceptualization of "memory" as an individual and internal faculty, people conceived of the temporal and transient dimension of their reality in terms of remembering activities that were (often indistinguishably) embedded in their forms of life. In early Greece, as Homer and Hesiod reported, mnemonic practices dwelt in the public space of conversation and interaction, of poetry, song, dance, ritual performance, and artifacts of art and architecture. The first meaning of mnemosyne is not "memory" but rather "remembrance," the exercise of an activity within a community. But with its written conceptualization, memory activities changed their location, taking up their abode in the individual mind. Locked up in the internal world of the person and reified in the form of a specific object called memory, they were reduced to just one element of a far more complex set of social practices. While early on, remembering meant listening to and understanding a voice, after the introduction of written records it meant looking something up in an inscribed record, which implied evaluating if and how accurate the inscription was read or "recalled." In this way, a broad spectrum of cultural practices of remembering and forgetting transformed into an aspect of cognition, of true or false knowledge.

One of the most amazing phenomena Danziger's historical memory parcour brings into prominence is that this idea, which is based on the experience of writing as a practice to preserve knowledge and experience - a practice of inscribing ("encoding"), preserving ("storing"), and reading ("decoding" or "retrieving") "information" — has served for more than 2000 years as metaphor, model, and empirical confirmation of the most fundamental Western idea of memory, namely as a storage, an archive of the past. No doubt, this is a long parcour. It follows the various gestalts of memory from Greek and Roman Antiquity (paying particular attention to Plato, the originator of the seemingly indestructible 
inscription metaphor for memory), Christian Middle Ages, the Renaissance, and Modern Times, to figures crucial for the 20th century sciences of memory such as Ebbinghaus and the members of the Göttingen School of experimental research who have determined the shape of academic memory psychology until today's cognitive and neuroscientific models. With each step in the development of new technologies of storing and inscription - based on materials such as stones, wax tablets, parchment, paper, books, libraries, print, photography, magnetic tape, film, digital computers, the internet, and technologies of brain imagining - new memory metaphors and models became available, even if all support the same basic vision of inscription and archive.

Still, it is astonishing to see how many different metaphors, models, and theories have been put forward to give shape to the peculiar idea of a storage container of the past. This plethora of conceptualizations - attempts at "domesticating memory," as Danziger puts it - marks a second level on which memory is historicized. From the very onset, writers, philosophers, scholars, and scientists have continuously re-constituted "memory" as an object of human knowledge and reflection. Traditionally, this is the focus of Geistesgeschichte or conceptual history, as well as of the more specific history of psychology (even if historians of psychology have for the most part ignored the study of memory). But Danziger's interest goes further. His point of departure is the insight that theoretical conceptions of memory, with all their pre-theoretical presuppositions, hidden metaphors, and unexplained philosophical assumptions, do not constitute an isolated domain, but are always to be seen in accordance with the exigencies and requirements of their time. These requirements are all but merely conceptual and academic. They reach beyond the field of theory and its history to the field of technology and that of culture, both with their own respective histories. At stake, then, is the particular constellation in which memory concepts, material technologies, institutional and cultural practices, performances of remembrances, and memory values are mutually interlinked. As far as I can see, it makes Danziger's book one of a kind in that it situates memory and remembering within the context of such a multifaceted historical episteme (which we might want to see as also encompassing literature and the arts that, particularly since modernism, have advanced our knowledge of the intricacies of human memory practices and their narrative fabric perhaps more than anything else).

Consider just one element of such interlinking: mnemonic values. Danziger describes them as culturally grounded assumptions about what is worth remembering, what ought not to be or need not to be remembered, what kinds of tasks practices of remembrance should be expected to serve. It is indeed hard to find a memory concept, a metaphor, a theory, an experiment, or a fMRI brain scan that does not echo cultural values. Ancient Greek writers expected memory (anamnesis) to offer a contemplative way to the deepest and primordial truths; Romans wanted it to be a rhetorical expedient for legal and political debates; the medieval cultivation of monastic memory was meant to foster the virtuous life and valued remembering as an act of emotional and spiritual immersion; the Renaissance practitioner of mnemotechnics, the "art of memory," appreciated memory as an intellectual construct, an object of deliberate invention meant to improve mnemonic and imaginative skills.

Again an entire new set of mnemonic values came about with the Industrial Revolution and the period of European Enlightenment. Rather than existential reflection, moral improvement, or aid for dialectical intellectual exercises, memory's significance now was 
to provide accurate factual knowledge. It was expected to work like a mechanical archive, a copying machine. This idea was in line with the influential empiricist view of memory as a inner storage for copies of sensory impressions and, at the same time, related to the new visual and auditory recording devices (such as camera and phonograph) and other technologies demanded by the expanding industrial and commercial institutions. On the "subjective side," this kind of memory work was supported by new educational institutions and methods and, not least, by the emerging academic discipline of psychology. In Ebbinghaus's memory experiments, which became the model for modern memory experimentation, the aim was not to investigate actual experiences of remembering or forgetting but to demonstrate successes (and failures) in accomplishing very specific memory tasks. As a consequence, the idea of a reified memory that was separated from the psychological, material, social, and cultural contexts in which people remember and forget became the hallmark of experimental psychology.

One great strength of the historical approach is that it reveals what Danziger calls the impermanence of human constructions. It anchors them in time, a time that is, as we know, always changing. Looking, from Danziger's perspective, at the present cultural episteme of memory and the many old and new fields of investigation that are part of it, it seems that the concept of memory is changing again. But this time, the change may be more profound and far-reaching than before; in fact, here we are dealing with a third meaning of historization, a third level on which the historical nature of memory is laid open. Neurosciences, new digital memory technologies, social and cultural memory studies, literature and the arts (and the investigation of their nexus with mind and culture): what recent developments in all of these fields appear to be radically challenging is the very notion of memory as an ontological entity on its own, a notion whose constitution in Western culture Danziger has reconstructed and whose variations run through the entire historical period he has covered in his book.

Challenged together with this notion is the idea that the complexity of the numerous forms and practices of human remembering can be explained in terms of storage and retrieval operations of an individual mind or brain, that is, as the workings of a particular archival entity in which "information" is "encoded," "stored," and "retrieved," to use again the traditional vocabulary. Instead, the focus shifts to remembering and forgetting as embedded activities that, mediated by mnemonic artifacts, sign and symbols systems, are carried out by people, and not brains, people who live in buzzing social and cultural worlds. To understand this present transformation of the notion of memory - which may result in its dissolution as such — as well as its many previous changes, Danziger's book is invaluable. Its originality, scholarship, and sophistication make it a classic both for Greek and Roman readers.

\section{References}

Danziger, K. (1990). Constructing the subject: Historical origins of psychological research. Cambridge, UK: Cambridge University Press.

Danziger, K. (1997). Naming the mind: How psychology found its language. London, UK: Sage. 